\title{
"We are still putting out fires": Considering educator intentionality in remote instruction during the COVID-19 pandemic
}

\author{
Natalie Sue Svrcek ${ }^{1}$ (D) Logan Rath $^{2}$ (D) Kathleen OImstead ${ }^{1}$ (D) \\ Kathleen Colantonio-Yurko ${ }^{1}$
}

Received: 29 January 2021 / Accepted: 13 July 2021 / Published online: 31 August 2021

(c) The Author(s), under exclusive licence to Springer Science+Business Media, LLC, part of Springer Nature 2021

\begin{abstract}
The COVID-19 Pandemic affected P-12 educators around the world, including an emergency move to remote instruction, inclusion of new technology tools to teach at a distance, and in many cases technology mandates for instruction. In the present study, we examine educators' self-reported survey responses about technology use during face to face and online instruction during the COVID-19 Pandemic. We use SAMR, a framework used to understand degrees of technology integration in teaching, as a way to interpret educators' responses and consider the ways that educators reported their use of technology in their face to face and online teaching.
\end{abstract}

Keywords P-12 educators · COVID19 $\cdot$ Technology $\cdot$ Teaching $\cdot$ Pandemic $\cdot$ SAMR model

Natalie Sue Svrcek

nsvrcek@brockport.edu

Logan Rath

1rath@brockport.edu

Kathleen Olmstead

kolmstead@brockport.edu

Kathleen Colantonio-Yurko

kyurko@brockport.edu

1 Department of Education and Human Development, SUNY Brockport, 350 New Campus Drive, NY 14420 Brockport, USA

2 Drake Memorial Library, SUNY Brockport, 350 New Campus Drive, NY 14420 Brockport, USA 


\section{Introduction}

"There is no right answer out there for this new problem our education system has to tackle."

-Educator Survey Excerpt

In March 2020, the global COVID-19 Pandemic gave rise to extreme quarantine measures enacted for public health and safety. Among these were the closing of schools, with many districts both across the nation and the globe shifting to remote, online instruction (Onyema et al., 2020). This change came quickly, with some educational institutions implementing this emergency shift in as little as one week - and with little to no training for educators in remote instruction (Hodges et al., 2020). The onset of the COVID-19 Pandemic has dramatically impacted education (Onyema et al., 2020; UNESCO, n.d.) - imposing great challenges for today's P-12 educators. Indeed, many educators presently continue to negotiate the complexity of connecting with students, students' families and caretakers, and colleagues remotely, in addition to finding ways to engage students in meaningful learning experiences from a distance. Moreover, the swift move to emergency remote teaching illuminated the need for an increased focus on the use of technology and digital tools in P-12 schools (Onyema et al., 2020).

Research conducted prior to the global pandemic has indicated that many educators have little to no professional development and technological support in distance education from their schools and districts (Beschorner \& Woodward, 2019). This gap in technological training has become more apparent-largely due to the unforeseen nature of the pandemic - which has led educators around the world to scramble to meet their students' learning needs during a crisis (Bozkurt \& Sharma, 2020). With recent public health mandates forcing educators from preschool to higher education to practice instruction in entirely online environments, we, as researchers and teacher educators, had a unique opportunity to gather feedback from educators working with students during the early stages of the COVID19 Pandemic.

The aim of this paper is to share educators' perspectives and experiences with technology, a shift to emergency remote teaching, and learning during this challenging educational landscape-ultimately to inform work in the fields of teaching and teacher education. Our goal is not generalizability nor is it to promote a single answer to the new problem of emergency remote instruction that we as educators encountered. Instead, we aim to understand, share, and learn from educators' experiences as we consider how to better prepare tomorrow's teachers to engage in effective and meaningful remote teaching-ultimately, leading to advancement in the field of education through the use of technology. The research question that guided this study was as follows:

In what ways did educators (classroom teachers, literacy specialists, and library media specialists) use technology during the COVID-19 Pandemic? 


\section{Theoretical and literature frameworks}

In the following section we use this literature and theory to examine how the COVID-19 Pandemic disrupted face-to-face education and forced many educators and students to engage with online and blended learning and teaching. Then, we draw on relevant research, theory, and writings to help build a picture of meaningful online course design.

\subsection{Teaching and COVID-19}

For this study, it is important to consider the ways that teaching has changed for P-12 educators during the COVID-19 Pandemic and how the pandemic has influenced that change. Hodges et al. (2020) and Bozkurt and Sharma (2020) note emergency remote teaching and online teaching are inherently different.

\subsubsection{An instructional shift to emergency remote teaching}

Online teaching is the result of careful planning and deliberate practice; however, emergency remote teaching is online teaching which was the result of "a crisis" (Bozkurt \& Sharma, 2020; Hodges et al., 2020). Traditionally, the shift to, "online or blended learning" is something that "requires a significant re-imagining"; however, many educators in March 2020 had to completely shift their current practices to online sans "thoughtful re-reimagining" (Code et al., 2020, p. 420).

A disparity in the reported perception of educators' preparedness for the shift to emergency remote teaching was illuminated in the literature. Aditya (2021) found that slightly more than $82 \%$ of their 62 K-12 educator participants in Indonesia, felt they had enough time to prepare their online learning materials. In contrast, Code et al. (2020) found the following five disruptions or changes for K-12 educators in their study of 42 secondary technology education teachers:

1. Curriculum-prescribed competencies are a casualty in pandemic-transformed pedagogy.

2. Equity and access to learning for all is undermined by pandemic-transformed pedagogy.

3. Pandemic-transformed pedagogy inhibits learning of unmotivated students.

4. Pandemic-transformed pedagogy has novelty, as well as limitations, in terms of effectiveness.

5. Educators' fears of loss of sustainability and quality of teaching are magnified by pandemic-transformed pedagogy. (pp. 426-427)

\subsubsection{Educators' work environment shifts online}

The COVID-19 pandemic also dramatically altered the working relationships of P-12 educators. Meeting during a planning or preparatory period, or informally 
stopping into a colleague's classroom after school was no longer a possibility after the shift to emergency remote teaching. Educators needed another way to make connections and continue to problem solve the day to day challenges of teaching during a global pandemic. It is no surprise that educators took to social media during the early stages of the pandemic to share information and connect with other educators, as Staudt-Willet (2019) previously found that educators exchange and build knowledge via Twitter. Trust et al. (2020) studied more than 10,000 tweets from the early stages of the pandemic that included the hashtags \#RemoteTeaching and \#RemoteLearning and the word teacher. Trust et al. (2020) found that educators used digital tools like Twitter and hashtags to communicate with one another, to share information helpful to educators shifting to remote teaching, and in some ways, connecting over digital spaces to show affinity and alignment. Bozkurt and Sharma (2020) posited that building supportive learning communities will be imperative to share lived experiences and learn from one another post COVID.

\subsubsection{Equity in education continues to be a concern}

Many scholars, educators, and districts remain concerned with issues of equity during the COVID-19 Pandemic. According to Aguliera and Nightengale-Lee (2020), "Across K-12 and higher educational settings, historically marginalized communities have been disproportionately affected by inequitable educational conditions" (p. 742). For many, these inequities have been compounded by the pandemic, despite early discussions that the pandemic would help "equalize" education. For example, students who relied on schools for food and shelter during the weekdays became a grave concern; also, inequitable access to technology resources in rural areas was illuminated (Aditya, 2021; Onyema et al., 2021); and UNESCO (n.d.) cited the following effects due to school closures: interrupted learning, nutrition, unequal access to digital learning portals, increased pressure on schools and school systems to remain open, and social isolation. Aguilera and Nightengale-Lee (2020) tasked educators and districts to take thoughtful steps to support all students during emergency remote teaching.

Online teaching environments can be made equitable for many students, particularly those with disabilities. However, the shift to emergency remote teaching is not the same as meaningful and purposeful online teaching (Bozkurt \& Sharma, 2020). When planning for online teaching, Thompson and Copeland (2020) argue that educators should be explicit about the instructional changes they make to online learning environments during emergency remote teaching as it helps students, particularly those with disabilities, recognize the way the course can support all learners.

\subsection{Technological determinism and technological instrumentalism}

Important to our study is the history of how educators and scholars determined the worth and impact of various technology innovations and tools. Many educators teaching during emergency remote teaching have been faced with making tough pedagogical choices. There are two main views of how technology and culture 
interact: determinism and instrumentalism (Carr, 2011). The former sets the position that the tool will be the driver of cultural change. The latter holds the tool as neutral, with the person being responsible for how the tool is used. Carr argues that technological determinism, the idea that technology drives the future of society, prevails over the course of history. Using the shift from primarily consuming printed words on a page to digital words on a screen, courtesy of the internet, Twenge (2017) posits that we are not consuming information as deeply and as such have changed as a culture, thus the current generation of children are different from previous generations. Lastly, Prensky (2012), a technological determinist, explored educational reform and how to teach digital natives, children who are currently in the school system and for whom technology has always existed as a major part of their lives. On the other hand, Cuban (1986) argues that instrumentalism is the prevalent view in education. Through an examination of the use of technological tools among educators over a 60 year period, he found that, regardless of the technology-radio, TV, and computers-teaching practices and the culture of the classroom dictated how the tools were used, and largely shaped their non-adoption for many years. This distinction informed the development of our survey used to explore participants' adoption of technology during emergency remote teaching.

\subsection{Instructor adoption of online learning}

Interestingly, many of the factors that prevent the adoption of technology are not related to the specific tools, but rather to the culture and workload of teaching itself. Twenty-five years ago, Olcott and Wright (1995) found four major concerns for faculty when considering participation in distance learning: promotion and tenure requirements, compensation, training, and release time for development. These concerns are not necessarily specific to the use of any one tool, but more to the cultural ethos of teaching in higher education. Many years later, Phillips et al. (2016) found that the workload of creating a blended course, one that is not fully online, involved more planning than for a face-to-face class, but allowed the instructor to focus on higher levels of learning. While our study focuses on P-12 educators and librarians, these trends in higher education are helpful to understanding the ways that educators have to use technology in their practice.

\subsection{SAMR model}

Central to our study is the SAMR Model of technology integration. SAMR, created by Ruben Puentedura (2015), is a classification schema to describe levels of technology integration when using technology in the classroom (all levels); thus, SAMR is hierarchical. SAMR is an acronym for the four proposed levels: substitution, Augmentation, Modification, and Redefinition. Central to understanding SAMR is the significance of the different levels. The most basic level, Substitution (S), is the lowest level of technology integration. In this instance, the technology is used as a substitution for the original, or analog, activity. Examples include typing instead of writing, reading on a screen instead of paper, or filling out a web form instead of a 
paper form. The next level, Augmentation (A), is when the technology augments the task. For example, creating a multimedia presentation that combines visuals with text or including hypertext (links) in a written document. The next two levels show that there is some fundamental shift in the task at hand so that it looks different than its analog counterpart. The third level is Modification (M), where the task is modified as a result of the introduction of technology. Collaborative writing on a Google doc is a prime example. In an analog world it would not be feasible to write together on the same piece of paper with a classmate. Finally, Redefinition (R), where the task is impossible without the use of technology. A virtual field trip to the pyramids of Egypt is one example. The technology that enables this virtual field trip is so integrated with the task that there is no acceptable analog alternative. While each of the individual pieces of the field trip might be able to be recreated offline, the product would be fundamentally different. In our study, we used SAMR as a lens to analyze and understand participants' reported technology use during the COVID-19 Pandemic.

\section{Methods}

\subsection{Study design}

The aim of this study was to reveal the experiences of P-12 educators (classroom teachers, content specialists, and librarians) using technology in the classroom, including the time periods before and during the move to emergency remote teaching due to the COVID-19 Pandemic.

Qualitative case study methodology (Creswell \& Poth, 2018) was employed to provide an in-depth understanding of the participants' experiences teaching with technology, with particular interest paid to educators' use of technology in light of the move to emergency remote teaching during the COVID-19 Pandemic. Our case is bounded (Creswell \& Poth, 2018) by educators who used technology in support of their teaching and experienced the move to emergency remote teaching.

\subsection{Context}

Our study took place at SUNY Brockport in Western New York. The COVID-19 Pandemic has created a unique setting for teaching and our research that has not presented itself before. Schools across the United States and the world were forced to move instruction to online formats regardless of the preparation or readiness of educators to make that transition.

\subsubsection{Positionality}

The authors all have experience in elementary or secondary settings (classrooms or libraries) and are currently teacher educators and researchers at a state college. We have seen first-hand the effects of the COVID-19 Pandemic on our teaching of 
Table 1 Educators' teaching experience

Table 2 Current positions of educators

\begin{tabular}{ll}
\hline Years & $\begin{array}{l}\text { Number of } \\
\text { participants } \\
(\mathrm{n}=95)\end{array}$ \\
\hline $0-5$ & 33 \\
$6-10$ & 20 \\
$11-20$ & 23 \\
More than 21 & 19 \\
\hline
\end{tabular}

\begin{tabular}{ll}
\hline Grade level & $\begin{array}{l}\text { Number of } \\
\text { participants } \\
(\mathrm{n}=95)\end{array}$ \\
\hline Elementary (P-6) & 37 \\
Middle (5-8) & 16 \\
High school (9-12) & 28 \\
All grade levels (P-12) & 5 \\
More than one level & 8 \\
No response & 1
\end{tabular}

teacher candidates and graduate students, the experiences of the researchers' children, and the educators we teach; therefore, we share an interest in learning about educators' decisions for technology to support their instruction. All four researchers identify as white, cisgender, middle class individuals - three are female and one is male.

\subsection{Participants}

P-12 educators (classroom teachers, content specialists, and librarians) were chosen for this study due to (1) technology becoming an integrated part of teaching, as well as (2) the abrupt transition to online instruction that took place in response to the COVID-19 Pandemic. The final sample for our study included 95 P-12 educators (31 classroom teachers, 1 literacy specialist, 61 school library media specialist/teacher librarians, and 2 who hold other positions). At the time of the study, our participants taught in a variety of school settings ( 9 in an urban setting, 57 in a suburban setting, 28 in a rural setting, and 1 in "other"). Additional descriptive details of our participants' teaching experience and grade level positions are located in Tables 1 and 2.

\subsection{Development of survey}

Survey questions were developed to understand educators' experiences using technology during teaching both before and during the COVID-19 Pandemic. A pilot version of the survey was developed and distributed to educators in higher education and P-12 in March of 2020. Based on feedback and initial results, open-ended and 
closed questions were designed by the research team (Creswell \& Poth, 2018) in order to better situate the survey within the P-12 context. Our survey instrument can be found in Appendix A.

\subsection{Data collection}

The survey was first distributed in July 2020 through an email message to education graduate students and alumni (P-12 classroom teachers, literacy specialists, and instructional coaches) from the past five years of the state college where all authors work. In October 2020, another iteration of the survey was distributed to school library media specialists/teacher librarians through surrounding regional education service centers which support area school districts, educators, and students and a professional school library media specialist organization listserv.

Responses were recorded from July 2020 through November 2020. We received 157 responses to our survey, however only 95 participants responded to the relevant survey questions which included information about technology and teaching. Ninety-five responses were considered valid $(n=95)$ and separated from the larger data set for analysis.

\subsection{Qualitative analysis}

With our research questions in mind, we began examining survey data with the intention to move from a general understanding of the data to a more specific and nuanced understanding (Creswell \& Poth, 2018). Data analysis included two stages.

\subsubsection{Stage 1}

First, we independently open-coded (Creswell \& Creswell, 2018) four survey questions that related to the technology that educators used during their face to face teaching, their online teaching, and in relation to the digital tools mandated from schools, administration, and school districts. Each researcher made notes about possible themes and patterns (Creswell \& Creswell, 2018). Our research team met to discuss our individual coding; this process allowed us to become generally familiar with the data, identify digital tools that educators used in their teaching, and identify illustrative quotes. After this stage of analysis, we turned our attention back to the data to inquire more specifically how educators were using technology to support their teaching.

\subsubsection{Stage 2}

Subsequently, during our next stage of data analysis we used SAMR (Puentedura, 2015) as a theoretical lens. During this second round of coding, we chose to focus our attention on survey questions which could help us understand how educators were using technology to support their teaching. We used two of the survey questions analyzed in Stage 1 related to the technology that educators used during their 
face to face and online teaching. Additionally, we added a survey question to our analysis that included educators' creative use of technology to enhance their students' learning. The two remaining questions from the first stage of our analysis, related to the digital tools mandated from schools, administration, and school districts, were omitted from our Stage 2 analysis due to the fact that the responses did not help us understand how educators used technology.

As we approached the data, we independently looked at the responses by participants and coded each of their responses using SAMR as a priori codes (Creswell \& Creswell, 2018). Our research team met again to discuss our individual coding. We found the ways we coded the data were inconsistent even though we were drawing from the same resources and understanding of SAMR. Much of the research team's discussion focused on the coding discrepancies and we discovered that because we were not able to identify some of the educators' intentionality in technology choices, we were having to assume their intentions. In other cases when the researchers agreed, the participant had explained the intentionality behind their choice in technology use. At this point, we came to the conclusion that we were able to identify different digital tools that P-12 educators used to support their teaching, both face to face and online, and in some cases, we could interpret the degree of classroom technology integration (Puentedura, 2015) if participants had provided their intentions for their technology choices.

\section{Findings}

The purpose of this study was to understand the technology choices of P-12 educators during the COVID-19 Pandemic as it related to supporting their instruction. In this section, we first present descriptive findings related to the experiences of P-12 educators in relation to their familiarity with a variety of modalities for teaching and the digital tools used by P-12 educators. Then, we share our findings as they relate to the importance of intentionality with technology choices. All data has been anonymized to protect our participants' identities.

\subsection{Descriptive findings}

In this section, we discuss educators' experience with a variety of modalities of instruction and digital tools. This data collected through our survey provides important context to interpret and understand educators' technology choices in teaching during the COVID-19 Pandemic.

\subsubsection{Modality of instruction}

To understand the choices related to technology that educators made during the COVID-19 Pandemic we must understand what modalities they had experiences using prior to the pandemic. Table 3 presents educators' experience with a variety of modalities prior to the move to emergency remote teaching due to the COVID-19. 
Table 3 Educators' experiences teaching with modalities prior to the COVID-19 Pandemic

\begin{tabular}{llc}
\hline Teaching modality & $\begin{array}{l}\text { Number of participants } \\
(\mathrm{n}=95)\end{array}$ & $\begin{array}{l}\text { Percentage of } \\
\text { participants (\%) }\end{array}$ \\
\hline Face to face & 91 & 95.8 \\
Online, live session (synchronous) & 14 & 14.7 \\
Hybrid: face-to-face in-person with online (asynchro- & 7 & 7.3 \\
$\quad$ nous) work & 4 & 4.2 \\
Hybrid: online live sessions (synchronous) with & & \\
$\quad$ asynchronous work & 13 & 13.7 \\
Online, no live sessions (asynchronous) & & \\
\hline
\end{tabular}

Participants had the ability to select more than one modality they had experience with

Educators had a variety of experiences with different modalities for teaching, however overwhelmingly educators had the most familiarity with face to face instruction with $95.8 \%$ of participants having experience with face to face teaching. This is not surprising as face to face instruction is a more traditional modality used in P-12 schools. Prior to the pandemic some participants had familiarity with digital modalities. Approximately, $15 \%$ of participants had familiarity with online synchronous sessions. Similarly, about $14 \%$ of participants had experience with online asynchronous sessions. Hybrid formats (face-to-face in-person with online asynchronous work or synchronous online sessions with asynchronous work) were the least familiar to our participants, with less than $8 \%$ of the participants having experience with this modality.

\subsubsection{Digital tools}

Regardless of experience with digital modalities for teaching or a desire to move instruction online, educators around the world were forced to make a major shift in their instruction (Onyema et al., 2020). Similar to Aditya's (2021) survey of 62 K-12 educators' readiness to conduct digital learning in Indonesia, we found educators used both synchronous and asynchronous modalities of teaching online during emergency remote teaching. Figure 1 presents the types of digital tools that educators used during emergency remote teaching due to COVID-19 and their frequency of use.

It is no surprise that educators frequently relied on asynchronous tools during the emergency shift to remote instruction such as posting written content to online classrooms (75\% of participants), posting teacher-made videos (69\%), and posting external videos (63\%). Other asynchronous tools used less frequently were discussion prompts with text replies (37\%) and discussion prompts with audio/video content $(33 \%)$. Similar to the previous tools discussed, educators were able to quickly move previous face to face student activities online.

Educators also relied on synchronous tools, or tools that would allow their students to interact with them live. Educators frequently utilized synchronous tools such as video chats (74\%) and live lectures (54\%). Less frequently, the technological 


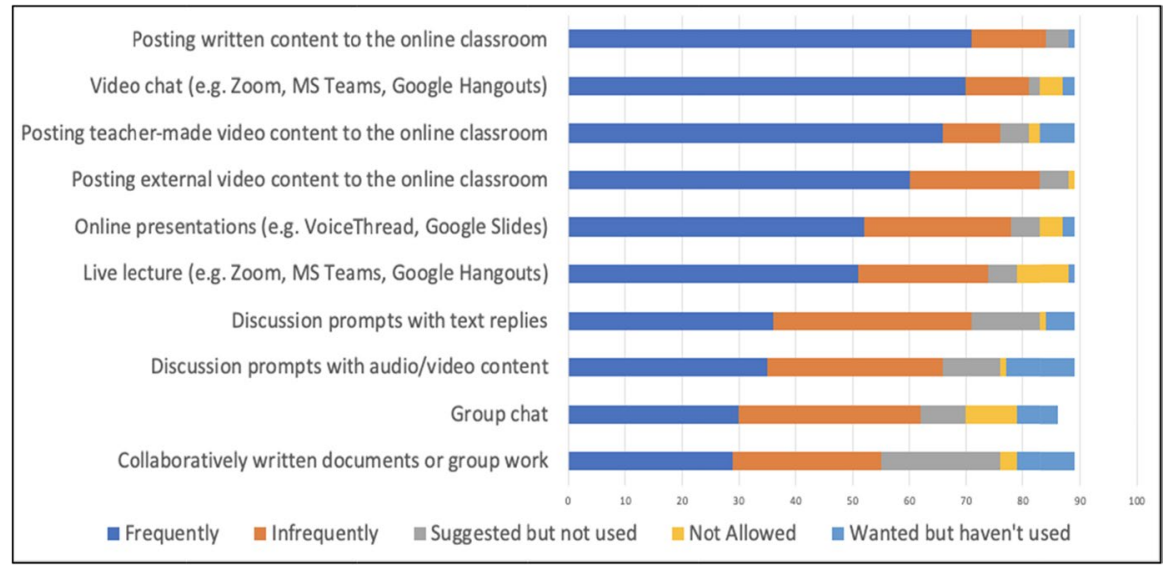

Fig. 1 Types of digital tools used during COVID-19

tool, group chat (32\%) was used. Aditya (2021) reported that most educators in Indonesia used online discussion during emergency remote teaching, however, specific synchronous tools were not discussed. Similar to the asynchronous tools, these tools allowed educators to interact with their students as if they were in class together.

Additional findings were that collaborative tools were used less frequently such as group chats (34\%) and collaborative online documents (27\%). Some digital tools were not permitted by school administration for some participants such as group chat $(9 \%)$, live lectures $(9 \%)$, online presentations $(4 \%)$, or video chats $(4 \%)$. In some cases, participants said live discussions were not allowed due to privacy concerns and pre-made lessons were the only permissible content, but in other cases, we are uncertain why certain digital tools were withheld from educators' toolboxes.

Due to the COVID-19 Pandemic, the shift to emergency remote teaching was swift and the participants noted that their administrations' expectations changed rapidly, at times day to day. Synchronous and asynchronous tools allowed educators to simulate what happens during face to face instruction (see Fig. 2). In instances such as these, the technology was used as a substitution for the original activity (Puentedura, 2015), the only difference was the technology mediating the educators' and students' interactions.

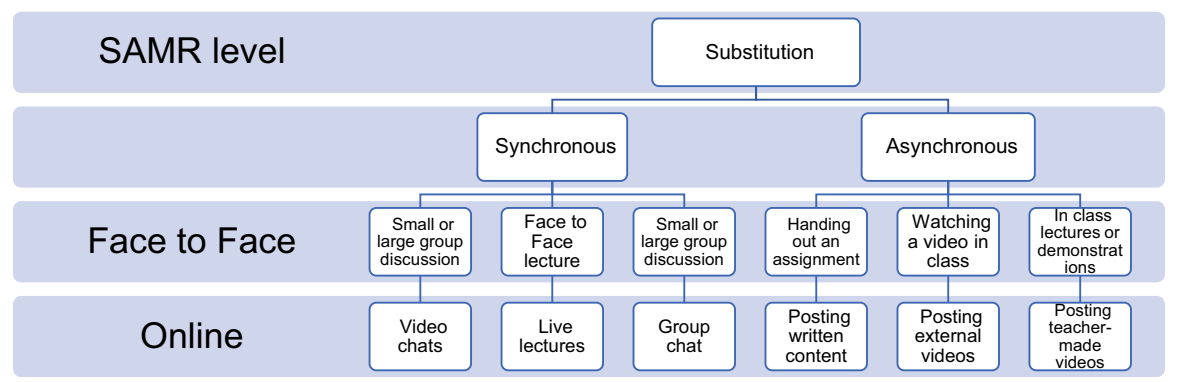

Fig. 2 Asynchronous and synchronous substitutions for face to face teaching methods 


\subsection{Integrating technology during the COVID-19 pandemic}

With the expeditious move to emergency remote teaching, it would not be overstepping to say that many educators felt like they were doing anything they could to ensure that their students were learning. In the previous section, we shared educators' experience with a variety of modalities teaching as well as a variety of digital tools they used while teaching remotely. Next, we present how our participants' used technology in their teaching during the COVID-19 Pandemic. To understand how our participants used technology in their teaching we analyzed the data using the SAMR Model (Puentedura, 2015) as a lens and thus present our findings within the four levels of the model.

\subsubsection{Substitution}

The most basic level of the SAMR Model, Substitution, uses technology as a substitution for the original activity. Figure 2 shares a variety of synchronous and asynchronous activities that our participants used. More, Fig. 2 shows the substitution, how the original activity (e.g., face to face lectures) was substituted for a similar activity using technology as the medium (e.g., live online lectures). It is important to note that educators found many ways to continue to teach by substituting an online instructional method for a face to face method, even in the move to emergency remote teaching. The affordances of these substitutions were (1) instruction could continue without having to be physically together, (2) instruction could take place synchronously or asynchronously, and (3) in many ways these substitutions likely felt like a seamless way to continue instruction that was already happening before the pandemic.

\subsubsection{Augmentation}

The next level, Augmentation, is when the technology supplements the original task. In this level, something additional is being added to the instructional model because of technology. While teaching during the COVID-19 Pandemic, our participants augmented their teaching using technology in a variety of ways such as presenting information using multimedia or integrating digital games as seen in Fig. 3. Using technology in these ways afforded educators additional functional improvement. For example, presentations with multimedia were able to incorporate multiple modalities at once, and digital games had the ability to provide interactive feedback to students.

\subsubsection{Modification}

When tasks and activities are modified as a result of the introduction of technology, the SAMR Model categorizes these shifts as the level of Modification. Technological modifications significantly redesign lessons and begin to transform teaching. Figure 4 displays a variety of activities that educators used during the pandemic that redesigned their previous face to face teaching methods. For example, using a learning management system that houses all course documents, resources, grades, and educator feedback modifies previous educator held materials and gradebook. Another example is the ability for students and educators to 


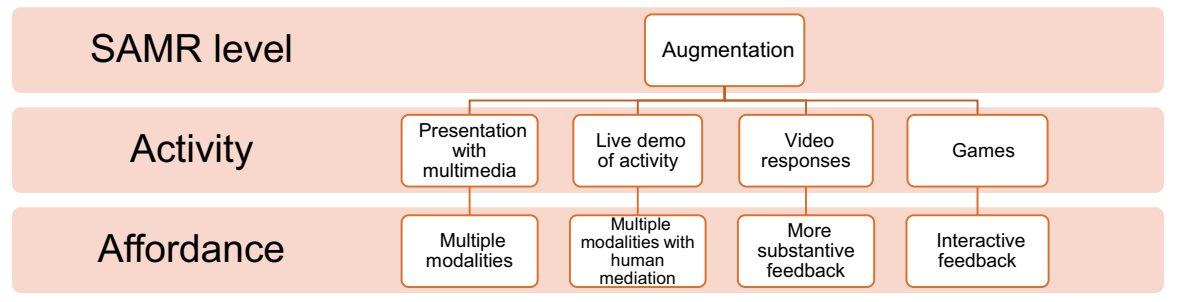

Fig. 3 Augmentation of face to face teaching methods

access online library materials-allowing access to a variety of print and multimodal resources at once. Using modifications for face to face teaching methods afforded access to resources, feedback, and additional opportunities for interaction.

\subsubsection{Redefinition}

Finally, we address Redefinition, relying on technology to reimagine the task. Figure 5 includes two activities categorized as a redefinition, virtual field trips and simulations. The ultimate goal of redefinition is to create new projects that were not possible without technology - a field trip in a global pandemic was inconceivable, however with technology a trip to a variety of places around the world became possible. We found the fewest examples of educators redefining their face to face teaching. A possible explanation for this was the speed that educators had to move their teaching online without time to dedicate to redefining their teaching.

\section{Discussion: "We are still putting out fires": Considering intentionality}

Discussions following our analysis illuminated educator intentionality as a vital component of online instruction, though admittedly intentionality was difficult to discern in some cases from the data provided by participants. As participants discussed their online teaching, they often merely listed technological tools they relied on-which we suggest overwhelmingly focused on the lower levels of the SAMR model-like

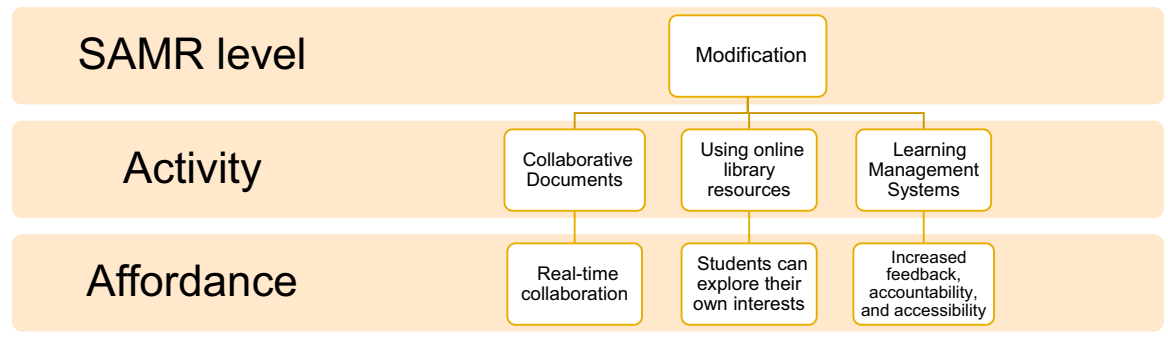

Fig. 4 Modification of face to face teaching methods 


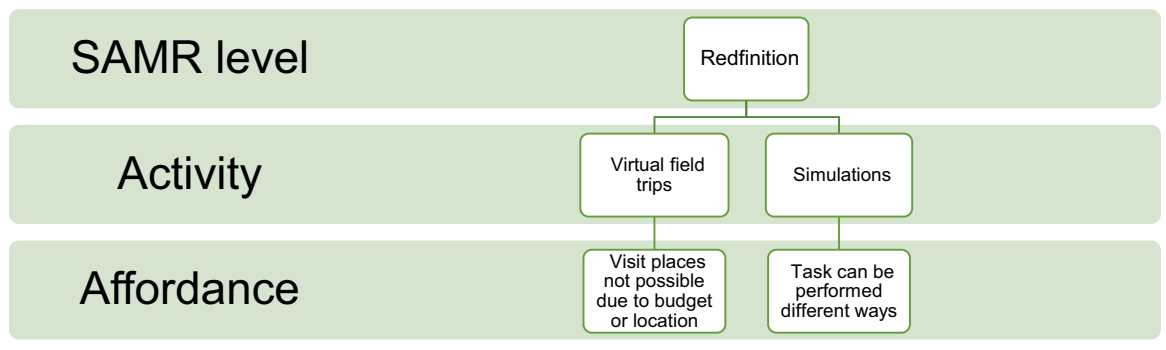

Fig. 5 Redefinition of face to face teaching methods

substitution and augmentation as noted in Figs. 2 and 3. Presumably, this focus on lower levels of technology integration is at least in part due to the lack of readiness and a need for additional training and support for educators (Mustapha et al., 2021).

We cannot assume the response of educators during emergency remote teaching would be the same if using online distance education, an alternative and flexible option for learners (Bozkurt \& Sharma, 2020). In some areas of the world, such as a study of 62 K-12 educators in Yogyakarta, Indonesia, teachers felt "psychologically, technologically, and pedagogically ready to conduct digital teaching and learning" (Aditya, 2021, p. 104). Bozkurt and Sharma (2020) asked, "While we rush to implement emergency remote teaching, are we focusing enough on learners and learning?" (p. iii). One of our participants answered this question as she discussed the challenge shifting to emergency remote teaching, "We haven't really achieved creativity yet. We are still putting out fires. Teachers are frantically trying to convert existing lessons to remote lessons, not really developing lessons from scratch." This sudden move to emergency remote teaching and the lack of preparation for educators made visible the complex process of planning and the designing of meaningful online instruction that was simply not possible. Emergency remote teaching was "an obligation," an immediate shift of modality in the middle of a crisis (Bozkurt \& Sharma, 2020).

Onyema et al. (2020) note, "The use of educational technologies facilitates online education, student-teacher interactions, connections, and relationships" (p. 114). Therefore, as many educators continue to evolve in their online instructional repertoire, intentionality must be considered essential to enhancing online instruction. Lyddon (2019) suggests technology integration is determined by a variety of complex factors which are "generally unconscious" and are largely ignored (p. 186) - this seems especially true when the goal for many educators during emergency remote teaching was simply to "convert" preexisting lessons. Thus, it may be powerful to encourage educators to revisit their personal beliefs about teaching and learning and share their stories (Cardinal et al., 2021)—with a goal of increased intentionality for improved remote instruction.

As Puentedura (2015) suggests, successful technology integration can have impacts on student outcomes-allowing students to transform learning and achieve in ways that they never could have without the technology. Similarly, Aditya (2021) found that educators too, believed technology can support students' motivation to learn. Effective online instruction provides learners with opportunities for "agency and choice" and thus, focuses on "learners' needs, learning 
contexts, and the availability and accessibility of the tools" (Bozkurt \& Sharma, 2020, p. ii). As new strains of COVID flourish (Weintraub, 2021), the future of face to face teaching is precarious - even with vaccinations currently in distribution-it seems likely that educators will be called upon once more to re-engage or continue utilizing remote teaching in the future.

\section{Implications}

For teacher educators and educators in P-12 schools, it is important to consider how we move forward, from what in many cases felt like a crisis being forced to move instruction online so expeditiously, to being intentional in our teaching as it relates to using technology and related tools. We know educators were looking for answers on how best to support their students during the pandemic; they sought knowledge and support via Twitter to "help them address pedagogical challenges" during the early stages of the pandemic (Trust et al., 2020, p. 157). The desire to support student learning with technology integration is present. However, additional support and preparation for educators to meaningfully and purposefully integrate technology is necessary (Bozkurt \& Sharma, 2020). When preparing for remote instruction, educators must engage in intentionality - thoughtful and purposeful planning for transformative student experiences — moving beyond substituting digital equivalents for live lessons to build a comprehensive online instructional repertoire.

Educators must begin to purposefully incorporate technology and related tools, not only in ways that enhance their teaching, but in ways that aim to reimagine and redefine their teaching. As Cardinal et al. (2021) remind, "Successful transitions to online teaching cannot only focus on mechanics and strategies; they also pay attention to the personal stories and beliefs that instructors hold about teaching and learning" (p. 47). We encourage the use of technology to create novel experiences that are not possible without technology for students (e.g., Redefinition). Next, we share some questions for educators to consider when integrating their instruction and technology.

\subsection{Thinking beyond tools to intentions: Questions for educators to consider}

1. What are the learning targets for my students and what goals do I want students to meet?

2. Which tasks lend themselves to substitution, augmentation, modification or redefinition based on the affordances of the available tools?

a. When is it appropriate to substitute a digital activity for an analog one?

b. How can I use technology to augment my learning activities?

c. Should my learning task be re-envisioned because of what a tool can do?

d. How can I use technology to engage students in novel experiences-ones beyond our regular classroom boundaries? 
3. Am I choosing a tool because it works with my learning target/objective?

4. In what ways can I use technology to differentiate instruction in ways I couldn't in the classroom?

5. Which choices will provide the most beneficial and enriching experiences to my students?

6. How can I integrate technology to increase students' motivation and build on their interests in new ways?

7. How can I use technology to build on students' strengths in new ways?

\subsection{Limitations}

One limitation of the present study is that when we asked what technology educators use in their face to face or online teaching, we failed to ask why they made those choices. By asking about the intentions behind technology usage, a more in depth understanding of the choices of P-12 educators would have been possible. Another limitation of our study was that we did not specifically ask our participants how the move to emergency remote instruction influenced their technology choices. With the current data, only assumptions are possible. At present, follow up interviews are being scheduled with participants to learn more about these important areas of focus. Finally, our participant pool was regionally defined, P-12 educators not associated with our state college or the regional education service centers in our area of the state were excluded. It would have been insightful to gain a more robust picture of educators' experiences, in our entire state, the country, or perhaps worldwide, had we expanded our survey distribution. Additionally, the success or effectiveness of technology was beyond the scope of this study.

\subsection{Future research}

A logical next step for our research is to investigate the emergent ideas from the data by interviewing willing participants. Qualitative interviews, although guided by an interview protocol, allow the researchers to ask follow up questions allowing participants to elaborate (Creswell \& Poth, 2018) more than a single response to a survey. Interviews would provide a more in depth understanding of the participants' use of technology to support their teaching. Moreover, interviews could also provide insight and help us understand how the move to emergency remote teaching due the COVID-19 Pandemic specifically influenced educators' use of technology. Additionally, the data from this study makes apparent the need to acknowledge the perspectives of all stakeholders affected by the move to emergency remote teaching including gaining the perspectives of school administration, students', and their parents and guardians. 


\section{Appendix A}

Technology and COVID-19 Teaching Survey

1. Are you a graduate or current student of the MS Ed in Literacy at [state college blinded for review]?

o Yes, I am a graduate of the program

o Yes, I am a current student of the program

o No

2. Are you located in the [city/state blinded for review] metro area?

o Yes

o No

This section of the survey contains questions that are demographic in nature.

3. How many years of teaching experience do you have?

4. How do you identify (race, identity, gender, etc.)?

5. What is your current age? Please enter a whole number (e.g., 34)?

6. Which of the following types of modalities have you taught prior to the COVID-19 pandemic?

o Face to face

o Online, live session (synchronous)

o Online, no live sessions (asynchronous)

o Hybrid: face-to-face in-person with online (asynchronous) work

o Hybrid: online live sessions (synchronous) with asynchronous work

7. Which of the following best describes your school?

o K-12, high school (grades 9-12)

o K-12, middle school (grades 6-8)

o K-12, elementary school (grades PK-6)

o Other

8. Which of the following best describes your current position?

o Classroom teacher

o Literacy specialist

o Instructional coach

o School Library Media Specialist / Librarian

We Are Still Putting Out Fires

9. Which grade(s) do you teach? If you are a secondary classroom teacher, please tell us the subject(s) you teach as well.

10. Which of the following best classifies the location of your workplace?

o Urban

o Suburban

o Rural

o Other 
13. In light of our current pandemic, which of the following technologies have you used or wanted to use?

\begin{tabular}{|c|c|c|c|c|c|}
\hline & Frequently & Infrequently & $\begin{array}{l}\text { Suggested but } \\
\text { not used }\end{array}$ & $\begin{array}{c}\text { Not } \\
\text { allowed }\end{array}$ & $\begin{array}{l}\text { Wanted but } \\
\text { haven't used }\end{array}$ \\
\hline $\begin{array}{l}\text { Posting written content to } \\
\text { the online classroom }\end{array}$ & o & o & 0 & o & o \\
\hline $\begin{array}{l}\text { Posting external video } \\
\text { content to the online } \\
\text { classroom }\end{array}$ & o & o & o & o & 0 \\
\hline $\begin{array}{l}\text { Posting teacher-made } \\
\text { video content to the } \\
\text { online classroom }\end{array}$ & o & o & o & o & 0 \\
\hline $\begin{array}{l}\text { Discussion prompts with } \\
\text { text replies }\end{array}$ & o & o & o & o & o \\
\hline $\begin{array}{l}\text { Discussion prompts with } \\
\text { audio/video content }\end{array}$ & o & 0 & o & o & o \\
\hline Group chat & 0 & 0 & o & o & o \\
\hline $\begin{array}{l}\text { Collaborative documents } \\
\text { (e.g., Google Docs, course } \\
\text { wikis) or group work } \\
\text { besides presentations }\end{array}$ & o & o & o & o & o \\
\hline $\begin{array}{l}\text { Online presentations (e.g., } \\
\text { VoiceThread, Google } \\
\text { Slides) }\end{array}$ & o & o & o & o & o \\
\hline $\begin{array}{l}\text { Video chat (e.g., Zoom, } \\
\text { MS Teams, Google } \\
\text { Hangouts) }\end{array}$ & 0 & o & o & o & o \\
\hline $\begin{array}{l}\text { Live lecture (e.g., Zoom, } \\
\text { MS Teams, Google } \\
\text { Hangouts) }\end{array}$ & o & o & o & o & o \\
\hline Other & o & o & o & o & o \\
\hline
\end{tabular}

14. How did you support teachers during the COVID-19 pandemic?

15. How did you support students during the COVID-19 pandemic? 
This section of the survey contains questions to understand how you use technology in your teaching.

11. In what ways, if any, is technology important to your face-to-face teaching?

This section of the survey contains questions related to your adoption of technology during the COVID-19 pandemic.

12. To what extent are the following important to the adoption of technology in remote teaching?

\begin{tabular}{c|cccc} 
& $\begin{array}{c}\text { Very } \\
\text { important }\end{array}$ & $\begin{array}{c}\text { Somewhat } \\
\text { Important }\end{array}$ & $\begin{array}{c}\text { Somewhat } \\
\text { unimportant }\end{array}$ & Unimportant \\
\hline $\begin{array}{c}\text { Ease of use for students } \\
\text { Ease of use for the teacher }\end{array}$ & 0 & 0 & 0 & 0 \\
Ability to provide direct instruction & 0 & 0 & 0 & 0 \\
$\quad$ Ability to interact with learners & 0 & 0 & 0 & 0 \\
$\begin{array}{c}\text { Extent to which the tool provides authentic } \\
\text { learning experiences }\end{array}$ & 0 & 0 & 0 & 0 \\
$\begin{array}{c}\text { The tool is available 24/7 } \\
\text { Maximizes student learning and } \\
\text { understanding }\end{array}$ & 0 & 0 & 0 & 0 \\
$\begin{array}{c}\text { Ability to connect with students using tools } \\
\text { they prefer }\end{array}$ & 0 & 0 & 0 & 0 \\
$\begin{array}{c}\text { Availability of technology support by my } \\
\text { school for the tool }\end{array}$ & 0 & 0 & 0 & 0 \\
$\begin{array}{c}\text { Ability to administer assessment or receive } \\
\text { assessment data }\end{array}$ & 0 & 0 & 0 & 0 \\
$\quad$ Other & 0 & 0 & 0 & 0 \\
$\quad$ & 0 & 0 & 0 & 0
\end{tabular}


This section of the survey asks questions about librarian involvement with the transition to remote teaching.

16. How has your school librarian supported students during the COVID-19 pandemic?

17. To what extent has your school librarian supported your transition to remote instruction?

This section of the survey contains questions about your job responsibilities during the COVID-19 pandemic.

18. Which of the following are expected of you by your school/district? Select all that apply.

o Teach remotely online (without live content)

o Teach remotely online (live class meetings at an assigned time)

o Hold live office hours

o Participate in live (synchronous) committee work

o Do committee work without actually meeting as a committee

o Participate in professional development/learning

19. What technology choices have you made to support your online teaching?

20. Tell us about creative ways you have used technology to enhance your online teaching.

21. What has your administration/school/district mandated in terms of your teaching? Please share any public communications (e.g., email, tweets) you would like to (please remove identifying information to protect your privacy)

22. Do you agree with the mandates from your district? Why or why not?

23. Is there anything else you would like to share?

24. If you would be willing to be contacted for a follow up interview, please enter your email address.

Availability of data and material Data made available upon request.

Code availability Not applicable.

Declarations

Conflict of interest Not applicable. 


\section{References}

Aditya, D. S. (2021). Embarking digital learning due to COVID-19: Are teachers ready? Journal of Technology and Science Education, 11(1), 104-116. https://doi.org/10.3926/jotse.1109.

Aguliera, E., \& Nightengale-Lee, B. (2020). Emergency remote teaching across urban and rural contexts: Perspectives on educational equity. Information and Learning Sciences, 121(5/6), 471-478. https:// doi.org/10.1108/ils-04-2020-0100.

Beschorner, B., \& Woodward, L. (2019). Long-term planning for technology in literacy instruction. The Reading Teacher, 73(3), 325-337. https://doi.org/10.1002/trtr.1828.

Bozkurt, A., \& Sharma, R. C. (2020). Emergency remote teaching in a time of global crisis due to Corona Virus pandemic. Asian Journal of Distance Education, 15(1), 1-6.

Cardinal, T., Kim, M., Pegg, J., \& Branch-Mueller, J. (2021). Being and becoming online teachers: A collaborative autobiographical narrative inquiry. Brock Education, 30(1), 30-50. https://doi.org/10. 26522/brocked.v30i1.819.

Carr, N. G. (2011). The shallows: What the Internet is doing to our brains. Norton.

Code, J., Ralph, R., \& Forde, K. (2020). Pandemic designs for the future: Perspectives of technology education teachers during COVID-19. Information and Learning Sciences, 121(5/6), 419-431. https:// doi.org/10.1108/ils-04-2020-0112.

Creswell, J. W., \& Creswell, J. D. (2018). Research design: Qualitative, quantitative, and mixed methods approaches (5th ed.). Sage Publications.

Creswell, J. W., \& Poth, C. N. (2018). Qualitative inquiry and research design: Choosing among five approaches (4th ed.). Sage Publications.

Cuban, L. (1986). Teachers and machines: The classroom of technology since 1920. Teachers College Press.

Hodges, C., Moore, S., Lockee, B., Trust, T., \& Bond, A. (2020). The difference between emergency remote teaching and online learning. Educause Review. Retrieved from https://er.educause.edu/artic les/2020/3/the-difference-between-emergency-remote-teaching-and-online-learning.

Lyddon, P. (2019). A reflective approach to digital technology implementation in language teaching: Expanding pedagogical capacity by rethinking substitution, augmentation, modification, and redefinition. TESL Canada Journal, 36(3), 186-200. https://doi.org/10.18806/tesl.v36i3.1327.

Mustapha, I., Van, N. T., Shahverdi, M., Qureshi, M. I., \& Khan, N. (2021). Effectiveness of digital technology in education during COVID-19 Pandemic. A bibliometric analysis. International Journal of Interactive Mobile Technologies, 15(8), 136-154. https://doi.org/10.3991/ijim.v15i08.20415.

Olcott, D., Jr., \& Wright, S. J. (1995). An institutional support framework for increasing faculty participation in postsecondary distance education. American Journal of Distance Education, 9(3), 5-17. https://doi.org/10.1080/08923649509526894.

Onyema, E. M., Eucharia, A. U., Gbenga, F. S., Roselyn, A. O., Daniel, O., \& Kingsley, N. U. (2021). Pedagogical use of mobile technologies during Coronavirus school closure. Journal of Computer Science and Its Application, 27(2), 97-110. https://doi.org/10.4314/jcsia.v27i2.9.

Onyema, E. M., Eucheria, N. C., Obafemi, F. A., Sen, S., Atonye, F. G., Sharma, A., \& Alsayed, A. O. (2020). Impact of coronavirus pandemic on education. Journal of Education and Practice, 11(13), $108-121$.

Phillips, J. A., Schumacher, C., \& Arif, S. (2016). Time spent, workload, and student and faculty perceptions in a blended learning environment. American Journal of Pharmaceutical Education, 80(6), 1-9. https://doi.org/10.5688/ajpe806102.

Prensky, M. (2012). From digital natives to digital wisdom: Hopeful essays for 21 st century learning. Corwin. https://doi.org/10.4135/9781483387765.

Puentedura, R. R. (2015). SAMR: A brief introduction. Retrieved from hippasus.com/rrpweblog/ archives/2015/10/SAMR_ABriefIntro.pdf.

Staudt Willet, K. B. (2019). Revisiting how and why educators use Twitter: Tweet types and purposes in\# Edchat. Journal of Research on Technology in Education, 51(3), 273-289. https://doi.org/10.1080/ 15391523.2019.1611507.

Thompson, K. M., \& Copeland, C. (2020). Inclusive considerations for optimal online learning in times of disasters and crises. Information and Learning Sciences, 121(7/8), 481-486.

Trust, T., Carpenter, J. P., Krutka, D. G., \& Kimmons, R. (2020). \# RemoteTeaching \& \# RemoteLearning: Educator tweeting during the COVID-19 pandemic. Journal of Technology and Teacher Education, 28(2), 151-159. 
Twenge, J. M. (2017). iGen: Why today's super-connected kids are growing up less rebellious, more tolerant, less happy and completely unprepared for adulthood and what that means for the rest of us. Atria Books. https://doi.org/10.4467/25436104hs.18.011.12312.

UNESCO. (n.d.). Adverse consequences of school closures. UNESCO. Retrieved June 10, 2021, from https://en.unesco.org/covid19/educationresponse/consequences.

Weintraub, K. (2021). New coronavirus variants aren't cause for alarm yet, but mutations could make COVID-19 harder to fight, experts say. USA Today. Retrieved January 22, 2021, from https://www. usatoday.com/story/news/health/2021/01/09/new-coronavirus-strains-variants-not-yet-cause-formore-covid-vaccine-concerns-experts-say/6575267002/.

Publisher's note Springer Nature remains neutral with regard to jurisdictional claims in published maps and institutional affiliations. 